\title{
Syntactic and Semantic Features of Three-Act Verbs in Russian and Uzbek Languages
}

\author{
Fakhriddin Israilovich Abdurakhmanov \\ Candidate of Pedagogical Sciences, Associate Professor, Uzbek State University of World Languages \\ Tashkent City, Uzbekistan \\ http://dx.doi.org/10.18415/ijmmu.v8i10.3129
}

\begin{abstract}
Research of syntactic-semantic analysis of three-act verbs consists in theoretical comprehension of transformational grammar in its enormous explanatory power. The core of transformational grammar is the idea of the core of the language, consisting of the simplest linguistic structures, from which all other linguistic structures of greater or lesser complexity can be derived. The problem of invariance, which is the central problem of modern structural linguistics, finds its most profound solution precisely in transformational grammar. The core of the language includes simple, declarative, active sentences, the socalled core sentences. In European languages, verb sentences are most common. They are followed by substantive, adjective and adverbial sentences in decreasing order of usage. In a simple sentence, the verb does not have to be the central node, but if there is a verb in the sentence, it is always the center of that sentence.
\end{abstract}

Keywords: Distributive-Transformational Scheme; Frame, Case Meaning; Actant, Semantic Class; Nuclear Construction, Transform; Actant Verb; Distribution of an Element; Structural Linguistics; Transformational Grammar

\section{Introduction}

In school grammar, there is no semantic analysis of cases, as well as analysis of case distribution (analysis of cases by environment). The scientific grammar of the Russian language has good distributional descriptions of the case system of the modern Russian language [1, p. 624]. The experience of the semantic study of cases belongs to Professor A.M. Peshkovsky [2, p. 544].

University textbooks, as well as academic grammars of the semantic analysis of cases do not contain. There is no semantic analysis of cases (except for some notes on the genitive case) and in the monograph of V.V. Vinogradov [3, p. 720].

In academic grammars of the Russian language, attention is very fluently drawn to qualitativeattributive prepositions. So, in "Russian grammar" spatial and temporal meanings are noted. Moreover, to analyze the semantics of prepositions, the reader is referred to the dictionary. There is no meaningful analysis of prepositions and associated case meanings in the syntax [4, p. 710]. As in the first volume, the 
syntax specifies only qualitative-attributive values without their distributive characteristics. The subject meanings of prepositional-case constructions are not indicated at all. This description is due to the lack of a rigorous model that includes an invariant mechanism that distinguishes between deep and surface structures.

\section{The Main Findings and Results}

The core of transformational grammar is the idea of the core of the language, consisting of the simplest linguistic structures, from which all other linguistic structures of greater or lesser complexity can be derived. The problem of invariance, which is the central problem of modern structural linguistics, finds its most profound solution precisely in transformational grammar.

The core of the language includes simple declarative (active) sentences - the so-called core sentences. In European languages, verb sentences are most common. They are followed, in decreasing order of usage, by substantive, adjective and adverbial sentences.

A verb can be imagined as a kind of "atom with hooks" [5, p. 250] that it possesses in order to attract actants to it and keep them to it - this is the essence of what is called the "valence" of the verb.

There are verbs without actants, i.e. verbs devoid of valence are impersonal, intransitive with one actant, transitive with two actants. In a sentence, the positions of actants are taken by nouns or their equivalents, which are directly subordinate to the verb.

From the point of view of semantics, the first actant is the subject of action, i.e. the one who performs the action; the second actant is an object influenced by a direct object of action, a direct addition; the third actant is an indirect or further object, in whose favor or to the detriment of which the indirect addition action is performed. However, the semantic content of the third actant is often broader [5, pp. 117130, 250-267].

The introduction of an auxiliary verb in mood or tense forms does not change anything in the organization of the actant structure: the actant structure of the sentence "he can give the book to his brother" is no different from the structure of the sentence "he gave the book to his brother".

The work uses the concept of a transformational attribute. The proposed definition is an adaptation of very complex formulations by Yu.D. Apresyan [6, p. 256], N. Chomsky [7], Z. S. Harris [8].

A transformational sign will be considered a pair of equivalent sentences (predicative phrases) combined into an invariant of the sign. The invariant is set by the semantics of the constituents themselves. Both sentences have the same inventory of direct components, identical at least in terms of the lexical meanings of the verb and actants.

Distributive - transformational scheme has the following indices: $N^{l}{ }_{i m}$ - subject in the nominative case in the position of the subject; $N^{2}$ - the first object; $N^{3}$ - second object; $V$ is a verb. To the left of the actant index, the preposition is indicated, its absence is not specifically indicated, to the right - the case is indicated by the initial letter of its name, for example: в - accusative case, $p$ - genitive case, etc. The animate or inanimate of the actant is taken into account, which is essential for the studied class of verbs. The prefix is indicated with the verb on the left.

A nuclear construction is a construction that denotes obligatory information: a noun in the nominative case + a verb + a noun in the accusative case without a preposition; nouns in other prepositional - case forms denote optional information. The basis for classification is the marked optional form representing the second entity. 
The definition indicates the minimum meanings of the action of each of the three actants, and for this it is necessary "to seek for each word a single nuclear" common "meaning that covers all its meanings" $[9$, p. 444].

Since in the definition of a semantic class, given by a transformational attribute, the minimum meanings of an action and actants are indicated, the definition can be called minimal semantisation. Establishing a correspondence between the elements of the definition and the significative meanings of verbs and their actants belonging to a given distributive-transformational scheme is an operator for generating a variant of the correct predicative phrase and can be called cross-semantisation.

In linguistics, semantic (content) and syntactic (formal) valencies are usually distinguished. At the same time, it is taken into account that the semantic valence is due to the lexical meaning, follows from it and characterizes this unit as a specific, different from others lexical-semantic unit [10, p. 442].

Consideration of semantic valence from a typological point of view, reflecting the deep structural and semantic connections of words, is characterized as universal for different languages of different systems. Syntactic valence is usually understood as the number of actants that the verb is able to control. And this "property is specific for each specific language, since it is a way and means of realizing meaningful (semantic) valence by means of a given language" [11, p. 148].

\section{Results}

The result of the research is that the work for the first time analyzes the semantic classes of threeactant verbs in the Russian and Uzbek languages, in establishing the principles of classification of semantic classes, in determining the terminological base for the problem under study, the collection of three-act verbs of the Russian and Uzbek languages by semantic filling, semantic classification of multiplace verbs of the Russian and Uzbek languages, the development of principles for the comparative study of three-actant verbs in multi-system languages, the determination of the transformational-distributive properties of the threeactant verbs in the Russian and Uzbek languages, as well as the identification and description of the similarities and differences in the transformational-distributive properties of the semantic classes of threeactant verbs in Russian and Uzbek languages.

\section{Conclusion}

This work is carried out in line with the semantic syntax, which considers the problems associated with the patterns of organization of the semantic side of the sentence. The apparatus of her research has not yet been finalized; therefore, there are several concepts of the semantics of a sentence. The most widespread is the denotative approach, which determines the relationship between the structure of a sentence and the structure of the situation it denotes. It forms the basis of this work, i.e. the semantic structure of the studied sentences is investigated in the aspect of the structure of the typical situations denoted by them. It is considered in abstraction from the modal and temporal characteristics of the proposal, since its denotative content does not depend on the given plans of the proposal.

The analysis of three-act sentences in the Russian and Uzbek languages shows that they belong to the number of complex syntactic objects of research. Their minimal structure includes the largest number of front components compared to other types of simple sentences. It is organized by triple predicates, the semantics of which requires three components: a subject and two objects. The subjective function is opposed to the object functions as the main one. The subject represents a participant (participant) performing an action indicated by a predicate (a statement made about a subject, a predicate), and, therefore, he must have signs of activity, intention and initiative in performing this action. Objects are dependent components: the subject's physical and mental activity is directed at them. The first object unites the 
participants, to which the subject's action is directly directed, who are completely covered by this action and, ultimately, undergo changes. The essence of the second object lies in the fact that it is a participant, in the direction or with the help of which the subject acts over the first object. He also reveals and clarifies the content of this action. These components constitute the structural minimum of three-act sentences. If they are present, the grammatical and semantic integrity of the structure is preserved. Outside the structural minimum are sirconstants - optional components that are not predetermined by the semantics of the verbal predicate. They refer to the entire content of the sentence as a whole, characterizing it in terms of place, time, etc. However, some of them are determined by the verb semantics, since their exclusion leads to a violation of the meaning of the sentence.

The criterion for highlighting three-act sentences in the text is syntactic valence, determined by the syntactic actants of the verb actually observed in the sentence: the subject and two additions that must correspond to the subject and objects. It allows you to draw the line between all the potential valencies of the verb and the valencies necessary for the creation and functioning of a well-defined sentence model in the text.

The study revealed that the languages being compared have similar syntactic ways of implementing semantic components. At the superficial level, a predicate is expressed by a verbal predicate, a subject is more often a subject, the first object is a direct object, and the second object is an indirect object. The difference between languages stems from the specifics of their grammatical structure. Thus, the analysis of three-act sentences shows that a complex semantic organization is hidden behind the simplicity of their grammatical composition.

The presences of the latter, as well as a large component composition of three-act sentences, determine their rich expressive capabilities. Such sentences more fully convey information about the state of affairs in reality compared to other types of simple sentences.

\section{References}

[1] Shakhmatov A.A. (2001) Syntax of the Russian language. Moscow: Editorial URSS. p. 624.

[2] Peshkovsky A.M. (2001) Russian syntax in scientific coverage. Moscow: Languages of Slavic culture. p. 544.

[3] Vinogradov V.V. (2001) Russian language: grammatical teaching about the word. Tutorial. 4th ed. Moscow: Russian language. p. 720.

[4] Russian grammar. In 2 t ed. Shvedova N.Yu. 1980. - Moscow: Nauka. Volume 1, p. 710.

[5] Tenier L. (1988) Fundamentals of Structural Syntax. - Moscow. p. 250.

[6] Apresyan Yu. D. (1967) Experimental study of the semantics of the Russian verb. Moscow: Nauka. p. 256.

[7] Chomsky N. (1962) Syntactic structures. New in linguistics - Vol. 2. - Moscow: Progress.

[8] Harris. Z.C. (1962) Co-occurrence and transformation in the linguistic structure. New in linguistics Vol. 2. Moscow: Progress.

[9] Fillmore Ch. (1981) The Case of the Case. New in foreign linguistics - Vol. 10. Moscow: Progress. p. 444. 
[10] Apresyan Yu.D. (1995) Lexical semantics. Synonymous means of language, Selected Works, Volume 1. Moscow: Eastern Literature. p. 442.

[11] Jamalova M.K. (2002) Actant and semantic structure of verbs of movement (displacement) in Russian and Rutul languages, dissertation for the degree of candidate of philological sciences. Makhachkala. p. 148.

\section{Copyrights}

Copyright for this article is retained by the author(s), with first publication rights granted to the journal.

This is an open-access article distributed under the terms and conditions of the Creative Commons Attribution license (http://creativecommons.org/licenses/by/4.0/). 